\title{
International medical graduate doctor to doctor telephone communication: a genre perspective
}

\section{Introduction}

\subsection{English for medical purposes: beyond doctor patient communication}

International medical graduates (IMGs), that is, doctors who have undertaken their medical training overseas, play an important role in filling health workforce shortages in developed countries such as the U.K., the U.S., Canada, Australia and New Zealand (Gorman \& Brooks, 2009; Wette, 2011). For example, in Australia about 39\% of the total medical workforce are IMGs, with the percentage increasing to $46 \%$ in some rural and remote areas (House of Representatives Standing Committee on Health and Ageing, 2012). Many IMGs come from lower income, less well resourced countries such as India, Bangladesh, Pakistan and the Philippines, where English is a minority language (Hawthorne, 2012; Lockyer, Fidler, de Gara, \& Keefe, 2010; Mullan, 2005). In Australia, there are ongoing concerns about IMGs' communication skills reported by clinicians (for example McDonnell \& Usherwood, 2008 ) and other institutional bodies addressing regulatory requirements (House of Representatives Standing Committee on Health and Ageing, 2012). Language proficiency, particularly conversational English, medical discourse, and different cultural expectations have all been identified as issues for IMGs practising medicine in their new host country (Hoekje \& Tipton, 2011; Pilotto, Duncan, \& Anderson-Wurf, 2007).

English for Medical Purposes (EMP) programs play a crucial role in providing opportunities for non English speaking background IMG doctors to develop the communication skills needed to meet the demands of the new healthcare context. To date, the focus of much research that has informed EMP is IMG doctor to patient communication, including appropriate use of medical language with patients (Dahm, 2011), empathy (Cordella \& Musgrave, 2009; O'Grady, 2011), language difficulties (Wette \& Basturkmen, 2006), and pronunciation and questioning (Ibrahim, 2001). There has been little focus in EMP on doctor to doctor communication, such as handovers or telephone communication. Doctor to doctor telephone consultations are common (Wadhwa \& Lingard, 2006) and are used to communicate about a wide variety of patient care issues (Car \& Sheikh, 2003). They can be source of risk for patient safety (Barenfanger et al., 2004; Rabøl et al., 2011). 
Studies of intercultural professional telephone communication suggest that there can be significant linguistic and cultural barriers to effective communication via the phone (see for example Bowles, 2006; Forey \& Lockwood, 2007); research into this aspect of medical communication is warranted for EMP.

\subsection{Patient safety training and communication protocols}

To manage the potential for miscommunication between health professionals about patient care, structured communication frameworks play a role in medical training. One communication protocol is SBAR: SBAR stands for 'Situation', 'Background', 'Assessment' and 'Recommendation' (Haig, Sutton, \& Whittington, 2006) where the elements indicate the content and the order of the information to be exchanged. Versions of SBAR have wide currency in Australia and the UK (Aldrich, Duggan, Lane, Nair, \& Hill, 2010; Marshall, Harrison, \& Flanagan, 2011; Veljii et al., 2008). Despite the high face validity of the SBAR model as a method of ideal communication, it is unclear how the model relates to real-world instances of effective clinical communication. The widespread use of communication protocols and the significance of doctor to doctor communication are important course design considerations for EMP practitioners addressing medical communication.

\subsection{Expert and learner professional discourse in medical education}

Interactional and communicative norms are markers of professional discourses (Sarangi and Roberts 1999). Learner professionals, such as junior doctors, need to gain expertise in clinical knowledge and practice but also proficiency in the communicative practices and genres of various clinical settings and specialties. Socialisation into professional practices and discourses has been traditionally viewed as taking place in the relationship between an apprentice or novice and a master or expert practitioner (in the medical context see for example, Paltridge, 2006). In teaching hospitals, more experienced clinicians play an integral role in junior doctor training. For example, Atkinson's description of case presentations in a haematology department exemplifies a microcosm of a community of practice whereby novice medical students learn not only from the expert consultant but through observation and interaction with more experienced but not yet fully expert registrars (1999). Erickson (1999) describes the indirect correction strategies of consultants supervising intern case presentations so that in spite of errors, the novice intern is still treated as a member of the community of practice. How IMG doctors, who are medically trained yet who may lack 
discursive and cultural expertise in the new clinical setting, are inducted into the discursive practices of their new setting is yet to be examined.

\section{Theoretical framework and methods}

\subsection{Study setting and patient safety training}

The aim of this study was to examine telephone calls initiated by non English speaking background IMG junior doctors to a more senior doctor (SD): we focused on how the IMG doctors achieved the goal of the interaction, namely to seek clinical advice on a deteriorating patient. The study was carried out at one metropolitan teaching hospital in Melbourne, Australia. It was conducted in a training setting as part of an existing patient safety training and transition program for International Medical Graduates (IMGs) at the hospital. The program was run at the simulation centre and was modelled on an undergraduate medical student patient safety program. The aim of the program was to ensure that IMGs working in the hospital network had the same level of skills in basic patient safety as domestically trained medical graduates. Between five and twelve IMGs and four to five instructors were involved in each training session. The program consisted of five one-day training sessions run on a monthly basis. The study was conducted over a 10 month period and encompassed two main intakes into the program. The training incorporated lectures, workshops covering clinical skills such as inserting an intra-venous line, as well as immersive simulated clinical scenarios. As part of the simulation training, participants received instruction in the use of ISBAR, a modified version of the SBAR communication protocol. This training was provided to 6 of the 8 IMGs prior to recording of the telephone interactions. Two IMGs received ISBAR training at a later date. These two IMGs were employed in the hospital and it is likely that they had some familiarity with the ISBAR communication tool, for example, through posters outlining ISBAR displayed at workstations within the hospital. By 2010, over $88 \%$ of clinical staff had received training in its use and many staff members had been issued with ISBAR lanyard cards (Marshall, 2010).

In the clinical scenarios the IMGs played the role of themselves, that is, junior doctors. Their roles and responsibilities in the simulation activity mirrored those of their real world clinical practice. In other words, if their patient deteriorated or if they required advice, they could call for assistance via the telephone from a more senior doctor who was not at the patient's bedside. The more senior doctor involved in the scenario took on various medical roles, for example, the role of an anaesthetic registrar if information about anaesthesia for the 
management of the patient was required. Each scenario involved a team of 3-5 participants who worked together to perform a range of clinical tasks to manage the patient such as monitoring the "patient 's" heart rate and checking to see the airways were open. The first named researcher provided language and communication training to junior doctors in the hospital but did not have an active role during the scenarios reported in this study.

Simulation training in general is used for the practice of clinical skills in highly realistic scenario based clinical environments with the aim of reducing clinical risk and improving patient safety. In this type of training, standardised clinical scenarios are used with a patient simulator (i.e. a mannequin whose vital signs are visible on monitors and can be manipulated by an instructor). The training room resembles the clinical setting. There is a wall phone near the "patient's" bed so that participants can call the "switchboard" (an instructor behind a one-way mirror) if they need to request any investigations or assistance.

\subsection{Genre analysis}

Genre analysis as developed within Systemic Functional Linguistics (SFL) was adopted as the theoretical framework as it incorporates a theory of language in context and emphasises the inter-relationship between the function of a text and its linguistic realisations. The study draws on the work of Martin and colleagues (Eggins, 2004; Eggins \& Slade, 1997; Martin, 1992, 1997, 2001). Genre is viewed as "a staged, goal-oriented, purposeful activity in which speakers engage as members of our culture”(Martin, 2001, p. 155). Additionally, Hasan's theory of generic structure potential (GSP) informed the development of the analytical framework for characterising the underlying structure of the texts (Eggins, 2004; Hasan, 1996). The GSP is an abstraction of the structural patterning of a text and therefore, represents a shift away from specific or actual examples of a genre to a more generalised level. While highlighting similarities between instances of a genre, the GSP also encompasses variation through the possibility of optional stages and by permitting a range of structural configurations.

As an analytical tool, the SFL genre approach allowed for a macro-level examination of the structure and stages of the text. The goal orientation of genre resonated with our aim of identifying how the interactants in the telephone calls achieved their aligned but different goals: that is, the IMG doctor's goal was to give information about the patient so that the SD 
could advise about patient care, whereas the SD's goal was to elicit sufficient information in order to ensure safe patient care. The study addressed two main research questions:

1. What is the generic structure of the effective IMG to senior doctor telephone interactions?

2. What are the genre features, including language, of the ineffective calls?

\subsection{Design of the study}

We adopted an integrated research design drawing on qualitative methods as well as genre theory. Qualitative methods provided a means of gaining an understanding of expectations and valued practices in this setting. Two main datasets form the foundation of the study: audio-recordings of the telephone calls between doctors as well as recordings of retrospective verbal reports (Dörnyei, 2007; Gass \& Mackey, 2000) by the SD involved in the telephone interaction on the calls. This paper addresses the above research questions through analysis of the telephone interaction data; it also draws on the findings of the verbal reports to develop the analytical framework. Due to space constraints, the findings from the verbal protocols are not presented here.

The study had ethics approval from both the hospital Human Research Ethics Committee B, and from the [name of university] as a Minimal Risk project.

\subsection{Participant naming and the term 'IMG'}

In the medical education and ESP literature, the term 'IMG' doctor tends to be used as if IMGs were a homogeneous group whereas IMG doctors can differ markedly in their cultural and linguistic backgrounds and where they have undertaken some or all of their medical education. They can also share cultural, linguistic and educational experiences with the majority population in the host country. Therefore, the label 'IMG' does not reflect the diversity of skills and training needs of even this sub-set of IMG doctors, yet it has been adopted in this article due to lack of feasible alternatives. While there is cultural, linguistic and educational diversity amongst IMG doctors, their geographical dispersal and small numbers at each clinical site in Australia and in other IMG destination countries mean that studies are unlikely to report IMG doctors in more identifying ways due to ethical and study design concerns. 
Furthermore, IMG doctors who have not completed their full Australian Medical Council registration can work in Australian hospitals as Hospital Medical Officers (HMOs) with limited registration. This means that they work under supervision of senior doctors as junior doctors. In Australia, the term junior doctor refers to newly graduated doctors who are completing their intern year and postgraduate training and who have not yet commenced specialist training. For an extended discussion of the term IMG doctor and its use, see Pill (2013).

\subsection{Participant recruitment and data}

The lead researcher at the simulation training centre, a practising anaesthetist, was approached by the first author to give his approval for the study. The first author then sought the participation of the sixteen IMG doctors who were enrolled in the program. She visited the orientation session and explained the study. Fourteen doctors gave their consent. Three participating IMGs were involved in a 6 month placement training program conducted by the hospital for IMGs who were seeking employment and medical registration in Australia. Eleven IMGs were employed as HMO doctors at the hospital. Eight of the fourteen participating IMGs made calls as part of the simulation. The IMGs who made the calls during the scenarios were from the following regions: South Asia (3), Northeast Asia (2), Southeast Asia (2) and Western Europe (1). Three of the calls were made by the three IMGs who were on the IMG placement program (Yao, Hua and Neha) while the remaining calls were made by 5 of the IMGs employed as junior doctors within the hospital network (Hilaria, Marieke, Farha, Indu and Amado). Table 1 provides an overview of the participants who made the calls. To ensure confidentiality, all names used are pseudonyms: the chosen pseudonyms reflect an IMG's country of origin. All participants were less than 40 years old. For the purposes of protecting the participants' anonymity, individual identifying information has not been provided. The more senior doctor receiving the calls also consented to participate in the study.

Table 1 Participants who made calls during the simulation training

\begin{tabular}{l|c}
\hline Participant characteristics of IMGs involved in the calls & $(\mathrm{n}=8)$ \\
\hline Female & 6 \\
\hline Male & 2 \\
\hline $\begin{array}{l}\text { On IMG placement program (not previously employed in an Australian } \\
\text { hospital) }\end{array}$ & 3 \\
\hline Employed as junior doctors & 5 \\
\hline
\end{tabular}


Twelve audio recorded telephone calls form the basis of the analysis. These calls were from six different simulated case scenarios (see Table 2 for a summary of the call and scenario information). As Table 2 shows, in three scenarios, the same IMG made two calls in the course of a scenario. The calls were recorded using a Trillium Recording adaptor and Olympus Digital voice recorder (WS-321M) attached to the fixed line telephone handset in the room used by the more senior doctor who received the call.

The audio recordings were transcribed using a transcription protocol which described temporal and sequential features. The transcripts were divided into speaker turns and these were numbered. The overall number of turns in each call as well as the duration of each call is shown in Table 2. 
Table 2 Summary of the 12 recorded telephone consultations.

\begin{tabular}{|c|c|c|c|c|c|}
\hline $\begin{array}{l}\text { Recording } \\
\text { number }\end{array}$ & Scenario & $\begin{array}{l}\text { IMG making } \\
\text { call } \\
E=\text { employed } \\
P=\text { placement } \\
\text { program }\end{array}$ & $\begin{array}{l}\text { Role of the senior } \\
\text { doctor }\end{array}$ & $\begin{array}{l}\text { Length } \\
\text { of call }\end{array}$ & $\begin{array}{l}\text { Number } \\
\text { of turns }\end{array}$ \\
\hline 1 & Case 1: patient with fever & $\begin{array}{l}\text { IMG } 1 \\
\text { Yao }(\mathrm{P})\end{array}$ & ICU registrar MET call & $06: 34$ & 149 \\
\hline 2 & $\begin{array}{l}\text { Case 2: assessment of } \\
\text { complex patient's fluid } \\
\text { status }\end{array}$ & $\begin{array}{l}\text { IMG } 2 \\
\text { Hua }(\mathrm{P})\end{array}$ & Anaesthetics registrar & $05: 35$ & 138 \\
\hline 3 & $\begin{array}{l}\text { Case 2: assessment of } \\
\text { complex patient's fluid } \\
\text { status }\end{array}$ & $\begin{array}{l}\text { IMG } 2 \\
\text { Hua }(\mathrm{P})\end{array}$ & Surgical registrar & 04:05 & 78 \\
\hline 4 & $\begin{array}{l}\text { Case 3: trauma } \\
\text { hypotension }\end{array}$ & $\begin{array}{l}\text { IMG } 3 \\
\text { Hilaria (E) }\end{array}$ & Surgical registrar & $04: 18$ & 107 \\
\hline 5 & $\begin{array}{l}\text { Case 4: trauma extradural } \\
\text { haematoma }\end{array}$ & $\begin{array}{l}\text { IMG } 4 \\
\text { Marieke (E) }\end{array}$ & Neurosurgical registrar & $02: 46$ & 66 \\
\hline 6 & $\begin{array}{l}\text { Case 4: trauma extradural } \\
\text { haematoma }\end{array}$ & $\begin{array}{l}\text { IMG } 4 \\
\text { Marieke (E) }\end{array}$ & $\begin{array}{l}\text { Anaesthetics registrar- } \\
\text { code blue }\end{array}$ & $01: 16$ & 34 \\
\hline 7 & $\begin{array}{l}\text { Case 2: assessment of } \\
\text { complex patient's fluid } \\
\text { status }\end{array}$ & $\begin{array}{l}\text { IMG } 1 \\
\text { Yao (P) }\end{array}$ & Surgical registrar & $03: 16$ & 50 \\
\hline 8 & $\begin{array}{l}\text { Case 2: assessment of } \\
\text { complex patient's fluid } \\
\text { status }\end{array}$ & $\begin{array}{l}\text { IMG } 5 \\
\text { Neha }(P)\end{array}$ & Radiology registrar & $00: 29$ & 10 \\
\hline 9 & $\begin{array}{l}\text { Case 2: assessment of } \\
\text { complex patient's fluid } \\
\text { status }\end{array}$ & $\begin{array}{l}\text { IMG } 5 \\
\text { Neha }(P)\end{array}$ & Surgical registrar & 02.21 & 51 \\
\hline 10 & Case 1: patient with fever & $\begin{array}{l}\text { IMG } 6 \\
\text { Farha (E) }\end{array}$ & $\begin{array}{l}\text { Medical registrar -MET } \\
\text { call }\end{array}$ & $04: 22$ & 100 \\
\hline 11 & Case 5: anaphylaxis & $\begin{array}{l}\text { IMG } 7 \\
\text { Indu (E) }\end{array}$ & Medical registrar & $02: 41$ & 84 \\
\hline 12 & $\begin{array}{l}\text { Case } 6 \text { hypoglycaemic } \\
\text { coma }\end{array}$ & $\begin{array}{l}\text { IMG } 8 \\
\text { Amado (E) }\end{array}$ & Medical registrar & $02: 30$ & 57 \\
\hline
\end{tabular}

The recordings are referred to as Recording $(\mathrm{R})$ and the number together with the IMG's pseudonym; (E) indicates an IMG was employed while (P) indicates he/she was participating in the Placement program e.g. Recording 4 or R4 Hilaria E. The shaded rows 9 and 11 are the effective calls described below.

\subsection{Development of the analytical framework and analysis}

In order to answer the first research question, What is the generic structure of the effective $I M G$-senior doctor telephone interactions? it was necessary to firstly identify which of the calls were effective. We sought a participant perspective to inform the linguistic analysis, for "if meaning is embedded in context... then discourse researchers need the help of 
professionals to understand what is going on in a given situation in order for their interpretation to be ecologically valid" (Sarangi, 2002, p. 105). As part of the larger study, the more senior doctor who received the calls reviewed each call and provided a global commentary on the quality of the call as well as a detailed verbal report. Due to space constraints only a summary of these findings are presented. The themes identified by the senior doctor that impacted on her assessment of the calls were: the IMGs' clinical knowledge, the structuring of information, language including fluency, the interaction between the two doctors, simulation and training, and to a lesser extent, the medical hierarchy. For an extended discussion of these themes, see Pryor (2013). The final section of the senior doctor's global commentary typically represented a summing up of ther overall impression of the call. In her concluding remarks, the SD explicitly gave positive evaluations to two of the twelve calls, that is, recordings 9, Neha (P) and 11, Indu (E). She explicitly identified recording 9 as "effective". In contrast, her negative evaluations were usually implied and could be inferred from the context. The two calls made by Neha and Indu formed the foundation for developing the model of the generic structure potential.

\subsubsection{The development of the generic structure potential of the intra-professional calls}

The development of the generic structure potential was a critical step in this study as the description of the generic stages provided the framework for examining all the calls. The approach to analysis of the generic structure was guided by Eggins and Slade (1997) and incorporated six steps ( $p$ p 230-235). The first step involved identifying that the texts appear to "move through predictable stages" (p. 231) and were therefore suitable for generic analysis. The overall purpose of the genre was then defined and the constituent stages were identified and assigned functional labels. These labels were intended to encapsulate how the stages contributed to achieving the primary aim of the genre. Further steps of the analysis focused on specifying the obligatory and optional stages of the generic structure and developing the structural formula for the Generic Structure Potential (GSP). The final step in the analysis involved identifying the lexico-grammatical features associated with the different stages of the schematic structure. We focused on language choices to do with how experience (or content) was realised or represented and on interpersonal meanings. Due to space constraints, the language features for each stage have only been reported in brief.

In determining the stages, we paid particular attention to how both participants worked together to achieve their purpose; the identification and functional labelling of the 
stages was therefore designed to reflect this emphasis on the co-constructed nature of the telephone call. This aspect of the analysis is informed by the work of Forey and Lockwood (2007) into call centre discourse. In assigning functional labels the researchers drew on their familiarity with the context based on their experiences as educators in the medical setting. The process of identifying and distilling the stages was an iterative one: the first author carried out the analysis then discussed this in detail with the second author.

To answer the second research question, What are genre features, including language, of the ineffective calls? the remaining calls were examined using the model of generic structure potential developed from the two effective calls. One of the ten calls (Recording 8 Neha) was eliminated from the dataset as the IMG participant had made the call to the wrong person, that is, to the radiology registrar instead of the radiographer. Nine calls therefore comprise the data for this section of the analysis.

\section{Results}

The results are presented firstly in terms of our findings on the generic structure of the effective telephone calls. This is followed by the findings on the genre and language features of the ineffective calls.

\subsection{The Generic Structure Potential (GSP) of Intra-professional medical telephone consultations}

The stages of the calls were identified on the basis of their function in contributing to the overall purpose of the genre and on their patterns of linguistic features.

Table 3 Generic stages of effective intra-professional medical telephone consultations.

\begin{tabular}{|c|c|}
\hline Generic stage and functional description & Examples \\
\hline $\begin{array}{l}\text { 1. Doctor Identification: Conveys } \\
\text { identifying information so that both } \\
\text { parties know to whom they are speaking }\end{array}$ & $\begin{array}{l}\text { IMG: Hi my name is Neha calling from surgical ward } \\
\text { SD: Oh hi um it's just the surgical reg calling I was paged } \\
\text { IMG: Yeah hh I'm uh I'm Neha one of the interns here }\end{array}$ \\
\hline $\begin{array}{l}\text { 2. Patient Identification: Provides } \\
\text { identifying information about the patient } \\
\text { and a summary of key clinical } \\
\text { background information }\end{array}$ & $\begin{array}{l}=\text { uh look I have a } 32 \text { year old who's uh about one week post-op } \\
\text { from from some lacerations and cellulitis to his left arm= }\end{array}$ \\
\hline $\begin{array}{l}\text { 3. Description of current clinical } \\
\text { presentation: Outlines patient's core } \\
\text { clinical issues and relevant management, } \\
\text { build up a picture of the patient's illness } \\
\text { for the senior doctor and orients them to } \\
\text { the junior doctor's level of medical } \\
\text { understanding }\end{array}$ & $\begin{array}{l}\text { IMG: he's still on epidural and uh just like last one one hour uh } \\
\text { he's quite unstable his blood pressure has dropped and f:: right } \\
\text { now it's eighty nine on fifty three } \\
\text { SD: oh right okay } \\
\text { IMG: Yeah. His stats are a bit low too like uh ninety two on } \\
\text { oxygen and he's still like conscious talking to us uh on } \\
\text { examination his uh tummy is not distended there is no sign like }\end{array}$ \\
\hline
\end{tabular}




\begin{tabular}{|c|c|}
\hline & he's having internal bleeding or something $=$ \\
\hline $\begin{array}{l}\text { 4. Request/purpose of call: Makes the } \\
\text { reason for the call explicit }\end{array}$ & $\begin{array}{l}\text { IMG: uh I was wondering if you: could come around and give us } \\
\text { a hand please }= \\
S D=\text { ok sure }=\end{array}$ \\
\hline $\begin{array}{l}\text { 5. Information gathering and checking: } \\
\text { to check and elaborate on previously } \\
\text { presented information and to explore } \\
\text { new aspects of the clinical situation }\end{array}$ & $\begin{array}{l}\text { SD: = What were his sats did you say? } \\
\text { IMG: = His sats at about-he's actually got-drop down to ninety } \\
\text { two actually } \\
\text { SD: ok and how much oxygen is he on? } \\
\text { IMG: He's on full flow. } \\
\text { SD: So fifteen litres? } \\
\text { uh yes }\end{array}$ \\
\hline $\begin{array}{l}\text { 6. Diagnostic Hypothesis: Demonstrates } \\
\text { junior doctor's clinical reasoning skills }\end{array}$ & $\begin{array}{l}\text { IMG: We think he's developing an allergic reaction to it }= \\
\mathrm{SD}:=\mathrm{ok}=\end{array}$ \\
\hline $\begin{array}{l}\text { 7. Management plan: Covers } \\
\text { management/treatment } \\
\text { recommendations }\end{array}$ & $\begin{array}{l}\text { SD: [yes I'd just hang a bag up and start running that in= } \\
J D=\text { okay= } \\
\text { SD: = fairly quickly if his blood pressure's eighty five } \\
=y e s= \\
\text { you need to run that in (to that) } \\
=\text { alright }=\end{array}$ \\
\hline $\begin{array}{l}\text { 8. Statement of intent: Describes action in } \\
\text { response to initial request for assistance } \\
\text { and signals interaction drawing to a } \\
\text { close }\end{array}$ & $\begin{array}{l}\text { SD : =I'm just in the middle of seeing another patient so I'll get } \\
\text { there as soon as I can but }= \\
=a: \text { lright }=\end{array}$ \\
\hline 9. Closing: Terminates the conversation & $\begin{array}{l}I M G \text { : thank you } \\
\text { SD: no worries bye }\end{array}$ \\
\hline
\end{tabular}

Our findings suggest that the generic structure potential of the two effective telephone calls between a more senior doctor and an IMG covered the following stages:

\section{Doctor Identification $\wedge$ Patient Identification $<$ Patient's Presentation $>\wedge$ Purpose of Call *Diagnostic Hypothesis $<\{$ Information Gathering and Checking ^ Management Plan $\}>^{\wedge}$ Statement of Intent ${ }^{\wedge}$ Closing}

The symbols used in the diagram are based on the conventions outlined by Eggins (2004). The caret symbol ${ }^{\wedge}$ indicates how stages are ordered with respect to another and this ordering is considered fixed and not reversible. The symbols $<$ and $>$ before and after a stage indicate that it is recursive. Parentheses \{\} enclose the constituent elements which can recur as a sequence. The symbol * is used for an unordered stage; however, this description is somewhat problematic as it suggests that the stage may occur in any position, when mobile elements are in fact only mobile within certain boundaries (Hasan, 1996).

Sequencing: The structural formula of effective calls indicates that the Doctor Identification is followed by the Patient Identification in that fixed order. The Patient's Presentation precedes the Purpose, although the former may be repeated immediately after the Purpose adding more detail. The Diagnostic Hypothesis is the least constrained element and can appear after the first two Identification stages or following the first Information Gathering 
and Checking stage; however, it is only mobile within these limits. Information Gathering and Checking and Management Plan must occur in that order with the possibility of iteration of the sequence. The Statement of Intent and final Closing occur in the order shown.

As the examples for each stage in Table 3 show, the calls between the two doctors are dialogic in nature throughout the generic stages. Table 4 illustrates the generic stages and maps the interactional dimension of the realisation of the stages for the IMG doctor and the senior doctor.

Table 4 Interaction across the generic stages of intra-professional medical telephone consultations

\begin{tabular}{l|c|l}
\multicolumn{1}{c|}{\begin{tabular}{c}
\multicolumn{1}{c|}{ INTERACTIONAL } \\
DIMENSION - IMG
\end{tabular}} & GENERIC STAGES & $\begin{array}{c}\text { INTERACTIONAL DIMENSION } \\
\text { - SD }\end{array}$ \\
\hline $\begin{array}{l}\text { Greets \& identifies self } \\
\text { Gives information about the } \\
\text { patient }\end{array}$ & PATIENT IDENTIFICATION & Acknowledges information \\
$\begin{array}{l}\text { States core clinical issues and } \\
\text { management strategies }\end{array}$ & PATIENT'S CURRENT & Acknowledges information \\
\hline $\begin{array}{l}\text { Requests advice or assistance } \\
\text { CLINICAL PRESENTATION }\end{array}$ & PURPOSE & Acknowledges information \\
\hline $\begin{array}{l}\text { Suggests possible cause } \\
\text { Answers questions, offers } \\
\text { information }\end{array}$ & DIAGNOSTIC HYPOTHESIS & $\begin{array}{l}\text { Accepts suggestion or offers } \\
\text { alternatives }\end{array}$ \\
\hline $\begin{array}{l}\text { Acknowledges } \\
\text { Acknowledges }\end{array}$ & MFORMATION GATHERING & $\begin{array}{l}\text { Requests information; clarifies, } \\
\text { checks, and restates }\end{array}$ \\
\hline $\begin{array}{l}\text { Expresses thanks } \\
\text { Says goodbye }\end{array}$ & STATEMENT OF INTENT & Gives instructions \\
\hline
\end{tabular}

A further finding on the Generic Structure Potential of the intra-professional calls has to do with the linguistic realisations of each stage. The opening and closing stages were characterised by ritualistic everyday exchanges, for example "Hi" and "Bye", whereas other stages contained distinct lexical patterns such as the Patient Identification stage, in which depersonalised patient information was provided, e.g. "a 32 year old", and included temporal and other circumstantial information. Politeness markers featured in the junior doctor's articulation of the Purpose stage whereas instructions by the senior doctor in the management phase were more directive but mitigated by adjuncts (e.g. I'd just run that in). Technical language featured predominantly in the Patient Identification phase, Patient's Current Clinical Presentation, Diagnostic Hypothesis, and Information Gathering and Checking 
phases; these phases also incorporated lay medical language used by both participants. While these calls were initiated by the need to seek advice on the management of a deterioriating patient, the Purpose and Management phases contained few overt adverbial and adjectival phrases indicating urgency.

\subsection{Results for the ineffective calls}

As a first step in the analysis, we identified which stages were present in the nine calls based on functional criteria, in other words, based on whether a stage broadly achieved its functional role in contributing to the overall goal of the text. Therefore, we did not take into account to what extent a stage was realised; that is, a stage may have fulfilled the purpose only superficially or partially, or how a stage was realised interactionally or in terms of the lexico-grammar. This was an iterative process and involved referring to both the GSP and feedback from the senior doctor involved.

\subsubsection{Presence of stages}

Table 5 shows the results for the presence of the generic stages from the GSP model where ' + ' indicates a stage is present and '-' indicates it is absent.

Table 5 GSP and presence/absence of stages in the ineffective calls

\begin{tabular}{|l|c|c|c|c|c|c|c|c|c|}
\hline STAGE & $\begin{array}{l}\text { R1 } \\
\text { Yao }\end{array}$ & $\begin{array}{l}\text { R2 } \\
\text { Hua }\end{array}$ & $\begin{array}{l}\text { R3 } \\
\text { Hua }\end{array}$ & $\begin{array}{l}\text { R4 } \\
\text { Hilaria }\end{array}$ & $\begin{array}{l}\text { R5 } \\
\text { Marieke }\end{array}$ & $\begin{array}{l}\text { R6 } \\
\text { Marieke }\end{array}$ & $\begin{array}{l}\text { R7 } \\
\text { Yao }\end{array}$ & $\begin{array}{l}\text { R 10 } \\
\text { Farha }\end{array}$ & $\begin{array}{l}\text { R12 } \\
\text { Amado }\end{array}$ \\
\hline $\begin{array}{l}\text { Doctor } \\
\text { Identification }\end{array}$ & + & + & + & + & + & + & + & + & + \\
\hline $\begin{array}{l}\text { Patient } \\
\text { Identification }\end{array}$ & + & + & + & + & + & + & + & + & + \\
\hline $\begin{array}{l}\text { Description } \\
\text { of } \\
\text { presentation }\end{array}$ & + & + & + & + & + & + & + & + & + \\
\hline $\begin{array}{l}\text { Purpose of } \\
\text { call }\end{array}$ & + & + & + & - & + & + & - & - & - \\
\hline $\begin{array}{l}\text { Information } \\
\text { gathering } \\
\text { and checking }\end{array}$ & + & + & + & + & + & + & + & + & + \\
\hline $\begin{array}{l}\text { Diagnostic } \\
\text { hypothesis }\end{array}$ & + & + & - & + & + & + & + & + & - \\
\hline $\begin{array}{l}\text { Management } \\
\text { plan }\end{array}$ & + & + & + & + & + & - & + & + & + \\
\hline $\begin{array}{l}\text { Statement of } \\
\text { intent }\end{array}$ & + & + & + & + & + & + & + & + & + \\
\hline Closing & + & + & + & + & + & + & + & + & + \\
\hline
\end{tabular}


These results suggest that in general the participants orient to the underlying generic structure of the telephone calls. However, one stage appears to be seen by both parties as less critical and that is the Purpose which is missing in 4 of the 9 calls. Using the functional purpose as the criterion for achieving a generic stage suggests that the majority of calls should represent successful and appropriate examples of the genre. However, closer examination of each stage of the calls showed problems with the realisation of stages.

\subsubsection{Realisation of stages:}

Problems with the realisation of stages occurred throughout the phone calls, including inappropriate brevity or length of a stage, and repetition of stages. In some instances, stages tended to be only minimally realised: for example below, only the first name is provided by the IMG junior doctor in the initial Identification stage:

\section{Recording 5 Marieke (E)}

1. IMG Hi, it's Marieke

2. SD Oh hi it's the neurosurgical registrar I was paged

In contrast, other stages such as the Description of the patient's current clinical presentation stage were extensively realised, incorporating redundant information; that is,

\section{Recording 10 Fara (E)}

11. IMG =and ${ }^{\circ} \mathrm{hh}<$ to be removed shortly>plus he's a::lso had a laparotomy, for::- he had an injury in the duodenum so:, that was repaired as well as he ha:d uh a small liver (line) which is treated conservatively he's been having uh temperature for the past two three days now, and uh we just uh looking through him. his sats have started falling at-it was about eighty nineth about fifte- ten minutes ago. //Now we've put in oxygen,for-at about 10 [1 i t re s]

12. SD [what eigh] ty nine?

13. IMG yeah it dropped in between.

14. SD Yeah

15. IMG we couldn't find the function-the oxygen connect the tube=

16. $\mathrm{SD}=\mathrm{Yep}=$

17. IMG =so now we've uh put the sucti-the oxygen up to about ten litres and the sats have picked up to ninety five ${ }^{\circ} \mathrm{hh}=$

18. SD =right,

19. IMG his BP's about ninety six by forty eight so we're giving him a bolus of fluid=

20. SD $=\mathrm{hm} \mathrm{hm}$

21. IMG he's still very tachy but with a pulse rate of one twenty six

22. SD right 
23. IMG ${ }^{\circ} \mathrm{hh}$

24. SD so:: what do you think's going on

25. IMG one second (we're) examining (9.9 -team members talking) uh-one minute (2.0) one->do you wanna talk to him<one minute // (2.4 talks to colleagues) he's got a CVC: catheter on.the uh right side=

26. SD $=$ uh huh=

27. IMG =and it's quite inflamed around that $=$

The GSP model only allows for the possibility of the repetition of two stages, that is, Information Gathering and Checking and the Management Plan stage; however, revisiting of other stages such as the Patient's current clinical presentation or the Diagnostic Hypothesis typically also occurred in the less effective calls, with the move back to previous stages initiated by the senior doctor.

There was considerable variation within the nine calls in terms of the extent to which they diverged from the structure potential of the genre. One call, Recording 5, was identified by the senior doctor as "overall a pretty good call" and the schematic staging adhered more closely to the GSP model than the other eight calls. The duration of this call at 166 seconds is also similar to the two effective calls (141 seconds and 161 seconds). Other calls deviated considerably from the predicted staging with differences apparent in multiple stages. This difference was generally reflected in the length of the call, with calls often taking longer than the two effective calls.

\subsubsection{Presence of teaching sequences}

A distinctive aspect of the majority of the less effective calls was the presence of teaching sequences, a feature that was absent from the two effective calls. Nearly all the less effective calls included instructional sequences during which the senior doctor used a variety of strategies to teach the more junior IMG about the patient's condition and the transfer of clinical information. The calls varied in the degree to which instructional sequences were present; in Recording 5 (Marieke) one example of instructional discourse could be identified in which the SD gives the diagnostic hypothesis after an Information Gathering and

Checking exchange. In contrast, multiple sequences were evident in Recordings 1, 2, 3, 4, 10 and 12. Recording 6 was the only one of the nine less effective calls which does not contain any identifiable teaching sequences. The senior doctor indicated in her feedback that she terminated this call quickly because she felt it was pointless to continue. Two main teaching 
approaches were evident: i) re-interpreting or re-casting information and ii) developing clinical reasoning skills.

\section{i) Re-interpreting or re-casting information}

A typical aspect of many of the less effective calls was the presence of exchanges where the senior doctor re-cast information previously presented by the IMG; that is, the senior doctor strategically reinterpreted aspects of the patient's clinical presentation. These sequences are characterised by the presence of the conjunctive adjunct so and relational processes which "decode known meanings and encode new meanings " (Butt, Fahey, Feez, Spinks, \& Yallop, 2001, p. 63) as well as material processes. Table 6 provides an example of this use of the conjunction so to interpret information and recast it in a more clinically meaningful way.

Table 6 Re-interpreting information

\begin{tabular}{lll}
\hline Turn & Speaker & Transcript R4- Hilaria (E) \\
\hline 16. & SD & and tell me um is he a- is he awake and talking at the moment?= \\
17. & IMG & = yes he's awake and talking (he's a) GCS of fifteen, \\
18. & SD & okay so his airway's patent, = \\
19. & IMG & his airway's patent. $=$ \\
20. & SD & =and he's breathing, $=$ \\
21. & IMG & yes. \\
22. & SD & and what are his oxygen sats at the moment? \\
23. & $I M G$ & u: $m$ at ninety four: with a mask on at fifteen maximum $=$ \\
24. & SD & =right so he's hypoxic on oxygen. \\
\hline
\end{tabular}

ii) Developing clinical reasoning skills

A second dimension of the less effective calls was the presence of interactional sequences in the call which functioned to accomplish the Diagnostic Hypothesis. In this stage, there were frequently disruptions to the expected generic flow initiated by the senior doctor. According to the GSP model, the Diagnostic Hypothesis is given by the IMG without a direct request. However, in many of the less effective calls this stage was absent or clinical information was incorrect. This resulted in the more senior doctor adopting a number of strategies to achieve this stage of the interaction.

For example, as shown in the excerpt from transcript 4 (Table 7), the senior doctor sought information on the junior doctor's evaluation of the clinical situation since the junior 
doctor did not volunteer this information. This was typically realised as an interrogative with the Mental process verb of cognition think, that is, so what do you think. The senior doctor also followed up with a diagnostic hypothesis and this was typically realised as Mental processes of thinking, for example in line 69 sounds like.. or modalisation of possibility could.

Table 7 Developing clinical reasoning skills

\begin{tabular}{|c|c|c|}
\hline Turn & Speaker & Transcript R4 -Hilaria (E) \\
\hline 61. & SD & okay and does he have lots of bruising $i$ \\
\hline 62. & $I M G$ & $u:::: h=$ \\
\hline 63. & $\mathrm{SD}$ & $=\mathrm{a}$ sore abdomen? \\
\hline 64. & $I M G$ & $\begin{array}{l}\text { he ha::s bruising on the right side of }{ }^{\circ} u h^{\circ} \text { - right side of the chest } \\
\text { he's got bruising yeah= }\end{array}$ \\
\hline 65. & SD & $=$ okay so what do you think's going on at the moment \\
\hline 66. & $I M G$ & $\begin{array}{l}\text { (.) um well uh we think that there } i \text { :s-it's a surgical abdomen. } \\
\text { from blunt trauma. u::m que:ry it's possible we:ll <we were } \\
\text { thinking about hemothorax> but the airway's clear there is good } \\
\text { air entry so: [um but] we }\end{array}$ \\
\hline 67. & $\mathrm{SD}$ & {$\left[{ }^{\circ}\right.$ okay $\left.^{\circ}\right] \quad$ yeah my- } \\
\hline 68. & $I M G$ & $\begin{array}{l}\text { my concern for him is that he's bleeding quite significantly=, } \\
=\text { yep }=\end{array}$ \\
\hline 69. & SD & $=$ because he sounds like he's in hypovolemic shock, \\
\hline 70. & $I M G$ & yeah, \\
\hline 71. & $\mathrm{SD}$ & low heart rate and blood pressure $=$ \\
\hline 72. & $I M G$ & $=y e a h$, \\
\hline
\end{tabular}

\subsubsection{Misunderstandings and language aspects}

Explicit misunderstandings related to phonological features were present in four of the nine calls (Recordings 2 Hua, 3 Hua, 5 Marieke and 12 Amado); however, these were rare. Three instances of overt communication breakdown due to phonological problems occurred in the two calls made by Hua. The following example (Table 8) shows how the IMG's pronunciation of the word machine caused confusion and required clarification. Problems with both syllable stress and the vowel sound of the second syllable in the context of grammatical errors resulted in comprehensibility difficulties for the senior doctor.

Table 8 Misunderstandings and language aspects 


\section{Turn $\quad$ Speaker Transcript (R2 Hua)}

78. SD

[have you checked the extent of the epidural whether it's working,

79. $I M G$ uh it is working and now the machine show is twelve,

80. SD (0.1) sorry the?

81. $I M G$ uh the machine's read record reading of the machine, is twelve. $=$

In Recording 5 Marieke misunderstood the critical distinction between hypo and hyper leading to a repair sequence, and one instance of unintelligible speech was noted in Amado's call. The less effective calls were frequently characterised by hesitations and sections of rapid speech. This is illustrated in the following excerpt from Recording 4 Hilaria.

IMG (.) um well uh we think that there i:s-it's a surgical abdomen. from blunt trauma. u::m que:ry it's possible we:ll <we were thinking about hemothorax> but the airway's clear there is good air entry so: [um but]

\section{Discussion}

The model of the Generic Structure Potential of the intra-professional telephone calls provides insights into the generic phases and unfolding of a professional discourse that plays a key role in relating patient information between clinical staff. The nine generic stages identified in the GSP as well as the interactional dimension is in stark contrast to the model of ISBAR or SBAR communication protocols to transfer patient information from one clinician to another. A principal difference between the SBAR protocol and the GSP of the intraprofessional calls is the monologic conceptualisation of the former compared to the dialogic unfolding of the latter, a point also highlighted by Eggins and Slade (2012) in relation to ISBAR and clinical handovers. These findings suggest that adapted versions of SBAR which include categories explicitly requiring the joint participation of both clinicians; for example, Agreed Action and Responsibility including read back strategies (Yee, Wong, \& Turner, 2009), may better capture the co-constructedness of the interactions. The modifications to SBAR suggested by Yee et al. also result in an extended protocol, which more adequately covers the key stages described using genre analysis than the version of ISBAR used in this study. Such insights from discourse analysis point to possible ways in which applied linguists could collaborate with healthcare practitioners to develop resources, such as communication tools, which are based on empirical evidence and grounded in descriptions of typical, actual practice. 
A distinctive feature of all but one of the ineffective calls is the presence of instructional episodes which could be identified during three stages; the Diagnostic Hypothesis, Information Gathering and Checking, and Management Plan. Since at one level of purpose the goal of the interaction is clinical problem solving and decision-making, it is not surprising that teaching should occur in precisely these stages as they can be viewed as the "nub" of the telephone consultation (Moore, 2003; Moore \& Tuckwell, 2006). The Diagnostic Hypothesis in particular warrants further discussion as it would appear to be a pivotal stage in the calls between the two doctors and not effectively accomplished by many of the IMGs. From a genre perspective, it would seem, based on the two effective calls, that the position of the Diagnostic Hypothesis is the least constrained of all the stages described by the GSP model and furthermore, it may be realised within two brief turns. Consequently, this stage may be less salient and more difficult for IMGs to identify in their everyday interactions with colleagues via the telephone. Additionally, intercultural differences in the structuring of information may also play a role (FitzGerald, 2003; Forey \& Lockwood, 2007) with some IMGs not adequately foregrounding critical information early in the telephone consultation or not explicitly stating uncertainty.

A further characteristic feature of these calls is the role of the more senior doctor in the interaction in which she frequently took on a dominant and directive role. The initial stages, the Identification stages and Patient's Presentation, tended to be partially realised with key information omitted or not fore-grounded by the IMG doctor. Because of the relationship between constituent elements, such deviations from the predicted generic staging influence following stages. In these instances, the senior doctor had to in essence, revisit aspects of these stages during frequently extended Information Gathering and Checking stages.

The discourse analysis of the intra-professional medical telephone consultation presented in this study provides another example (cf Paltridge, 2006) of socialisation into professional practices and discourses between a novice and expert. In Atkinson's (1999) study, registrars learn from consultants whereas our study shows an example of an apprenticeship genre in which less senior doctors, that is a registrar, provides clinical guidance to a more junior medical colleague. In the effective calls in our study, the less experienced doctors seek advice from a senior colleague. In contrast, the less effective calls served a dual purpose; in addition to functioning as vehicles for medical problem solving, the calls also operated as educational tools. These realisations can be seen as examples of the 
apprenticeship genre which incorporates both clinical and educational aims (Spafford, et al., 2006) such as the extended teaching sequences to develop clinical reasoning skills. However, it is not clear how successfully the educational aims are realised in these instances which involve a high pressure and complex work environment. Two IMGs made two calls during a scenario and in both cases the second call was still highly problematic. This suggests that when the calls functioned as an apprenticeship genre with its twin aims of doing and learning, the IMGs oriented towards achieving workplace goals and the imperative of doing overrode the goal of learning. While the IMGs in this study were all junior doctors, it is not clear to what extent their performance differs from locally trained junior doctors and comments from the SD frequently emphasised the commonality between both groups of novice practitioners.

Difficulties with language have been commented on in the literature and accent is one area that has been discussed as a barrier to effective communication for IMGs (Dorgan, Lang, Floyd, \& Kemp, 2009; Hoekje,2007 ; Sommer, Macdonald, Bulsara, \& Lim, 2012; Tipton, 2005; Woodward-Kron, Stevens, \& Flynn, 2011). However, explicit misunderstandings due to pronunciation problems were very infrequent in this context. This finding resonates with research into intercultural call centre (Forey \& Lockwood, 2007) and aviation discourse (Kim, 2012) where difficulties with "traditional notions of poor language skills i.e. poor grammatical knowledge and poor pronunciation" (Forey \& Lockwood, 2007, p.323) were not identified as major causes of communication breakdown. While misunderstandings were rare in this study, problems with the phonological realisation of the content, for example fluency, were evident and may have impacted more subtly on the interaction.

\section{Conclusion and limitations}

This paper examined telephone calls of IMG junior doctors to a senior colleague to seek assistance with managing a critically ill (simulated) patient. The research approach adopted was genre analysis in order to explore how interactants achieved the goals of the interaction. Two outcomes of the research are a provisional description of the generic structure of an intra-professional medical telephone consultation, including the interactional dimensions of stages, and their salient language features. The research findings identify discourse patterns evident in the weaker performances. 
These findings have a number of benefits and implications for EMP practitioners. On a theoretical level, they provide insights into a core communicative task of junior doctors, namely a consulting telephone interaction with a senior doctor; to date this genre has not been explored to the best of our knowledge. The genre description embedded in the medical context provides a unique resource as a teaching tool. While we do not advocate explicit teaching of each step identified, we believe that participants' greater awareness of the crucial but problematic stages, such as the Diagnostic Hypothesis including its function and linguistic realisations as well as the associated interactional roles of the two doctors, would be beneficial to IMG doctors participating in EMP courses. Programs could incorporate examples of more and less successful realisations drawn from the data for discussion, including a focus on the language features. Our experience on this project of collaborating with professionals from another discipline also highlighted an important practical benefit of taking a genre approach to analysis. Assigning functional labels to stages which are clearly related to the task to be accomplished meant that findings were accessible to professional practitioners from non-linguistic backgrounds (Moore \& Tuckwell, 2006).

There are a number of limitations to the study which point the way to future research. Genre analysis as developed within SFL provided a valuable framework for this study and was a first step to understanding the telephone interactions. Findings emphasise the importance of knowledge and knowledge construction in the telephone consultations. Since the study findings suggest that some calls represent examples of instructional discourse, further analysis of interpersonal meanings may provide valuable insights into how role relationships are established and negotiated between a junior and senior doctor, particularly when the senior doctor takes on a teaching role in the interaction. Feedback data from the IMGs would also enhance the explanatory value of the study which could further inform the development of EMP materials and courses. Future studies could also investigate how the performance of the IMG junior doctors compares to locally trained junior doctors.

\section{Acknowledgments}

We wish to acknowledge the ongoing support and clinical insights of Dr Stuart Marshall from the Monash Medical Centre; the advice of Professor Tim McNamara, University of Melbourne; and the International Medical Graduate doctors and senior doctor who participated in this study. 


\section{References}

Aldrich, R., Duggan, A., Lane, K., Nair, K., \& Hill, K. (2010). ISBAR: a tool for improving communication with patients. Paper presented at the International Forum on Quality and Safety in Healthcare.

Atkinson, P. (1999). Medical discourse, evidentiality and the construction of professional responsibility. In S. Sarangi \& C. Roberts (Eds.), Talk, Work and Institutional Order: Discourse in Medical, Mediation and Management Settings (Vol. 1). Berlin: Mouton de Gruyter.

Barenfanger, J., Sautter, R. L., Lang, D. L., Collins, S. M., Hacek, D. M., \& Peterson, L. R. (2004). Improving Patient Safety by Repeating (Read-Back) Telephone Reports of Critical Information. American Society for Clinical Pathology, 121, 801-803.

Bowles, H. (2006). Bridging the gap between conversation analysis and ESP - an applied study of the opening sequences of NS and NNS service telephone calls. English for Specific Purposes, 25(3), 332-357.

Butt, D., Fahey, R., Feez, S., Spinks, S., \& Yallop, C. (2001). Using Functional Grammar: An Explorer's Guide (2nd ed.). Sydney: National Centre for English Language Teaching and Research, Macquarie University.

Car, J., \& Sheikh, A. (2003). Telephone consultations. (Information in practice). British Medical Journal, 326(7396), 966(964).

Cordella, M., \& Musgrave, S. (2009). Oral communication skills of international medical graduates: Assessing empathy in discourse. Communication \& Medicine, 6(2), 129142.

Dahm, M. (2011). Exploring perception and use of everyday language and medical terminology among international medical graduates in a medical ESP course in Australia. English for Specific Purposes, 30(1), 186-197.

Dorgan, K. A. P., Lang, F. M. D., Floyd, M. E., \& Kemp, E. P. R. N. (2009). International Medical Graduate-Patient Communication: A Qualitative Analysis of Perceived Barriers. Academic Medicine, 84(11), 1567-1575.

Dörnyei, Z. (2007). Research Methods in Applied Linguistics. Quantitative, Qualitative, and Mixed Methodologies. Oxford: Oxford University Press.

Eggins, S. (2004). An Introduction to Systemic Functional Linguistics (2nd ed.). London: Continuum International Publishing Group. 
Eggins, S., \& Slade, D. (1997). Analysing Casual Conversation. London: Equinox Publishing Ltd.

Eggins, S., \& Slade, D. (2012). Clinical handover as an interactive event: Informational and interactional communication strategies in effective shift-change handovers. Communication \& Medicine, 9(3), 215-227.

Erickson, F. (1999). Appropriation of voice and presentation of self as a fellow physician: Aspects of a discourse of apprenticeship in medicine. In S. Sarangi \& C. Roberts (Eds.), Talk, Work and Institutional Order: Discourse in Medical, Mediation and Management Settings. Berlin: Mouton de Gruyter.

Fitzgerald, H. (2003). How different are we? Spoken Discourse in Intercultural Communication. Clevedon: Multilingual Matters Ltd.

Forey, G., \& Lockwood, J. (2007). "I'd love to put someone in jail for this": An initial investigation of English in the business processing outsourcing (BPO) industry. English for Specific Purposes, 26(3), 308-326.

Gass, S., \& Mackey, A. (2000). Stimulated Recall Methodology in Second Language Research. Mahwah, New Jersey: Lawrence Erbaum Associates.

Gorman, D., \& Brooks, P. (2009). On solutions to the shortage of doctors in Australia and New Zealand. Medical Journal of Australia, 190(3), 152-156.

Haig, K., Sutton, S., \& Whittington, J. (2006). SBAR: A Shared Mental Model for Improving Communication Between Clinicans. Journal on Quality and Patient Safety, 32(3), 167-175.

Hasan, R. (1996). The nursery tale as a genre. In C. Cloran, D. Butt \& G. Williams (Eds.), Ways of Saying: Ways of Meaning - Selected Papers of Ruqaiya Hasan (pp. 51-72). London: Cassell.

Hawthorne, L. (2012). International medical migration: what is the future for Australia? Medical Journal of Australia Open, 1(Suppl 3), 18-21.

Hoekje, B. (2007). Medical discourse and ESP courses for international medical graduates (IMGs). English for Specific Purposes, 26, 327-343.

Hoekje, B., \& Tipton, S. (Eds.). (2011). English Language and The Medical Profession: Instructing and Assessing The Communication Skills of International Physicians (Vol. 5). Bingley, UK: Emerald Books.

House of Representatives Standing Committee on Health and Ageing. (2012). Lost in the Labyrinth: Report on the inquiry into registration processes and support for overseas trained doctors: Commonwealth of Australia. 
Ibrahim, Y. (2001). Doctor and patient questions as a measure of doctor-centredness in UAE hospitals. . English for Specific Purposes, 20(4), 331-344.

Kim, H. (2012). Exploring the construct of aviation communication: A critique of the ICAO language proficiency policy Unpublished $\mathrm{PhD}$, University of Melbourne, Melbourne. Lockyer, J., Fidler, H., de Gara, C., \& Keefe, J. (2010). Learning to practice in Canada: The hidden curriculum of international medical graduates. Journal of Continuing Education in the Health Professions, 30(1), 37-43.

Marshall, S. (2010). Developing and implementing education to teach structured communication for clinical communication. Paper presented at the Healthcare Communication Symposium.

Marshall, S., Harrison, J., \& Flanagan, B. (2011). The Evolution of a Communication Tool to Improve Clinical Safety. Southern Health/Monash University.

Martin, J. R. (1992). English Text: System and Structure. Philadelphia: John Benjamins Publishing Company.

Martin, J. R. (1997). Analysing genre: functional parameters. In F. Christie \& J. R. Martin (Eds.), Genre and Institutions: Social Processes in the Workplace and School (pp. 339). London: Continuum.

Martin, J. R. (2001). Language, Register and Genre. In A. Burns \& C. Coffin (Eds.), Analysing English in a Global Context. London: Routledge.

McDonnell, L., \& Usherwood, T. (2008). International medical graduates: Challenges faced in the Australian training program. Australian Family Physician, 37(6), 481-484.

Moore, A. (2003). The discursive construction of treatment decisions in the management of HIV disease. Unpublished $\mathrm{PhD}$, Macquarie University, Sydney.

Moore, A., \& Tuckwell, K. (2006). A tenorless genre? Forensic generic profiling of workers' compensation dispute resolution discourse. Linguistics \& the Human Sciences, 2(2), 205-232.

Mullan, F. (2005). The Metrics of the Physician Brain Drain. The New England Journal of Medicine, 353(17), 1810-1818.

O'Grady, C. (2011). Teaching the Communication of Empathy in Patient-Centered Medicine. In B. Hoekje \& S. Tipton (Eds.), English Language and the Medical Profession: Instructing and Assessing the Communication Skills of International Physicians (Vol. 5). Bingley, UK: Emerald Group Publishing.

Paltridge, D. (2006). Prevocational medical training in Australia: where does it need to go? Medical Journal of Australia, 184(7), 349-352. 
Pill, J. (2013). What doctors value in consultations and the implications for specific-purpose language testing. University of Melbourne. Unpublished $\mathrm{PhD}$. dissertation.

Pilotto, L., Duncan, G., \& Anderson-Wurf, J. (2007). Issues for clinicians training international medical graduates: a systematic review. Medical Journal of Australia, 187(4), 225-228.

Pryor, E. (2013). An exploratory study of intra-professional, intercultural medical telephone consultations. University of Melbourne. Unpublished MA (Research) dissertation.

Rabøl, L. I., Andersen, M. L., Østergaard, D., Bjørn, B., Lilja, B., \& Mogensen, T. (2011). Descriptions of verbal communication errors between staff. An analysis of 84 root cause analysis-reports from Danish hospitals. BMJ Quality and Safety, 20(3), 268274.

Sarangi, S. (2002). Discourse Practitioners as a Community of Interprofessional Practice: Some Insights from Health Communication Research. In C. N. Candlin (Ed.), Research and Practice in Professional Discourse (pp. 95-136). Hong Kong: City University of Hong Kong Press.

Sommer, J., Macdonald, W., Bulsara, C., \& Lim, D. (2012). Grunt language versus accent: the perceived communication barriers between internaional medical graduates and patients in Central Wheatbelt catchments. Australian Journal of Primary Health, 18(3), 197-203.

Spafford, M., Schryer, C., Mian, M., \& Lingard, L. (2006). Look Who's Talking: Teaching and Learning Using the Genre of Medical Case Presentations. Journal of Business and Technical Communication, 20(2), 121-158.

Tipton, S. (2005). Improving international medical graduates' performance of case presentations. Journal of Applied Linguistics, 2(3), 395-406.

Veljii, K., Baker, G. R., Fancott, C., Andreoli, A., Boaro, N., Tardif, G., et al. (2008). Effectiveness of an Adapted SBAR Communication Tool for a Rehabilitation Setting. Healthcare Quarterly, 11, 72-79.

Wadhwa, A., \& Lingard, L. (2006). A qualitative study examining tensions in interdoctor telephone consultations. Medical Education, 40(8), 759-767.

Wette, R. (2011). English Proficiency Tests and Communication Skills Training for Overseas-Qualified Health Professionals in Australia and New Zealand. Language Assessment Quarterly, 8(2), 200-210. 
Wette, R., \& Basturkmen, H. (2006). Two perspectives on the language difficulties of Overseas Trained Doctors: Evidence from role plays. New Zealand Studies in Applied Linguistics, 12(2), 64-77.

Woodward-Kron, R., Stevens, M., \& Flynn, E. (2011). The medical educator, the discourse analyst and the phonetician: A collaborative feedback methodology for clinical communication. Academic Medicine, 86, 565-570.

Yee, K. C., Wong, M. C., \& Turner, P. (2009). "HAND ME AN ISOBAR": a pilot study of an evidence based approach to improving shift-to-shift clinical handover. Medical Journal of Australia, 190(11), S121-S124. 


\section{University Library}

\section{- M M N E R VA A gateway to Melbourne's research publications}

Minerva Access is the Institutional Repository of The University of Melbourne

Author/s:

Pryor, E;Woodward-Kron, R

Title:

International medical graduate doctor to doctor telephone communication: A genre perspective

Date:

2014-07-01

Citation:

Pryor, E. \& Woodward-Kron, R. (2014). International medical graduate doctor to doctor telephone communication: A genre perspective. ENGLISH FOR SPECIFIC PURPOSES, 35 (1), pp.41-53. https://doi.org/10.1016/j.esp.2013.12.001.

Persistent Link:

http://hdl.handle.net/11343/58555 